\title{
Formar o mestre na universida de: a experiência paulista nos anos de 1930
}

Olinda Evangelista

Universidade Federal de Santa Catarina

Resumo

Este artigo apresenta resultados de pesquisa sobre a formação universitária docente na década de 1930, no Brasil. A investigação realizou-se coligindo fontes produzidas no período, tanto as originárias da instituição em estudo quanto as advindas de periódicos, legislação, jornais e obras educacionais, entre outras. A partir do corpus documental arrolado, pode-se verificar que em 1933, no estado de São Paulo, inaugurou-se a primeira escola de nível superior para o preparo do professor, o Instituto de Educação, originário da reforma educacional de Fernando de Azevedo. Em 1934 foi incorporado à Universidade de São Paulo e, em conjunto com a Faculdade de Filosofia, Ciências e Letras, responsabilizou-se pelo preparo docente em nível universitário. No IEUSP institucionalizou-se a primeira geração de professores universitários voltados à formação de professores primários e secundários, projeto enraizado no debate intelectual ocorrido especialmente nos anos de 1920. Embora uma das respostas à demanda pela profissionalização docente e modelo para outras iniciativas, o Instituto foi encerrado em 1938. Forças políticas ligadas ao estado intervencionista de Ademar de Barros e à Igreja Católica finalizam, em 1938, a primeira experiência brasileira de formação de professores em nível universitário.

P a lavras-Chave

História da Educação - Formação do Professor - Instituto de Educação.

\footnotetext{
Correspondência:

Olinda Evangelista

Trav. J asmim dos Poetas, 85 -

Campeche

88.063-110 - Florianópolis - SC

e-mail: olinda@ brasilnet.net
} 


\section{Educ ating the teacher at the University: the experience of São Paulo state in the 1930s}

Olinda Evangelista

Universidade Federal de Santa Catarina

Abstract

This article presents results of a research on teacher university education in Brazil in the 1930s. The investigation was carried out gathering information sources from that period, including documents produced by the institution under study, as well as from periodicals, legislation, newspapers, and educational literature, amongst others.

From the documental corpus so gathered it was observed that in 1933, in the state of São Paulo, the first higher education school for the formation of teachers created was the Instituto de Educação (Institute of Education), stemming from the educational reform of Fernando de Azevedo. In 1934 it was incorporated to the University of São Paulo and, together with the School of Philosophy, Sciences and Literature, was responsible for the higher education of teachers. At the Institute of Education of the University of São Paulo was established the first generation of university teachers devoted to the education of teachers for the primary and secondary school, a project that had its roots in the intellectual debate that took place especially in the 1920s.

Although the Institute constituted one of the answers to the demand for teacher professionalization and had been a model for other initiatives, it was closed down in 1938. Political forces linked to the interventionist government of A demar de Barros and to the Catholic Church put an end in 1938 to the first Brazilian experience of higher education for teachers.

Keyw ords

History of education - Instituto de Educação - University of São Paulo. 
0 objetivo deste artigo é apresentar resultados de pesquisa sobre a formação universitária do mestre na década de 1930, no Brasil. A partir de 1933 no estado de São Paulo inaugurou-se a primeira escola - o Instituto de Educação - de nível superior para o preparo docente, originária da reforma educacional empreendida por Fernando de Azevedo. Em 1934, tal escola foi incorporada à Universidade de São Paulo. A universitarização do preparo do professor ocorreu em cursos de diferentes matizes e em conjunto com a Faculdade de Filosofia, Ciências e Letras da USP. Destacam- se, aqui, a constituição da primeira geração de professores universitários, bem como a formação disciplinar dos professores no Instituto de Educação da USP IEUSP. Essa experiência encontra raízes no debate intelectual ocorrido mais particularmente nos anos de 1920. A despeito de ser uma das respostas à demanda por qualificação profissional, e do peso que essa formação vinha tendo como modelo para outras experiências, o Instituto teve sua vida violentamente encerrada.

O debate nos anos 1920

Projetos de formação do magistério em nível superior, no Brasil, antecedem os anos de 1920. Em São Paulo, em 1890, Caetano de Campos, diretor da Escola Normal da Capital, defendeu a criação de um curso normal superior, modelo para a organização do sistema de ensino e de laboratórios para a formação de professores. A idéia concretizou-se na Lei $n^{\circ} 88$, de 1892 , prevendo um curso superior anexo à Escola Normal, que não funcionou (Tanuri, 1979).

Essa década inaugurou nova denominação para essa instituição com a criação, por Sampaio Dória, de uma faculdade de educação para "aperfeiçoamento pedagógico e cultural geral" com o fito de formar inspetores, diretores de escolas normais, ginásios e grupos escolares, além de professores para escolas complementares (Lei 1.750, de 8 de dezembro de 1920). A crítica acusou esse projeto de não se preocupar com os al tos estudos desinteressados, centrais em muitas das propostas em circulação. Em 1925, por meio do Decreto estadual $n^{\circ} .3 .858$, de 11 de julho, gestão Carlos de Campos, com Pedro Voss na direção da Instrução Pública, reaparece o projeto que mais uma vez não se realizou. Essas leis, além de resultarem dos projetos em disputa quanto à formação docente, possibilitaram debates e críticas a partir dos quais se gestaram propostas de qualificação que encontrariam nos anos de 1930 momento privilegiado de concretização.

Dentre as críticas ao modelo de qualificação então vigente, destaca-se a formulada no inquérito sobre a instrução pública, realizado em São Paulo, em 1926, pelo jornal 0 Estado de S. Paulo, sob coordenação de Fernando de Azevedo. ${ }^{1}$ Os intelectuais que nele depuseram, renomados nos meios acadêmico e político, trataram a questão articuladamente aos acontecimentos educacionais do momento e referindo - a aos vários níveis do sistema de ensino. Denomina-se a unidade para formação superior do magistério de Faculdade de Filosofia, Ciências e Letras, Faculdade de Educação, Faculdade de Ciências e Letras, Faculdade de Filosofia e Letras, Escola Normal Superior, Faculdade de Pedagogia e Cursos Superiores de Ciências, designações derivadas dos dissensos e consensos entre seus propugnadores.

As posições defendidas não deixam dúvidas quanto à força que adquiriu a idéia de formação do professor em nível superior, especialmente na universidade. Embora a maioria tenha salientado a formação do docente secundarista, o professor primário e os técnicos de ensino também foram vistos como profissionais a serem formados nesse nível. No entanto, nem todas as proposições somaram preparo técnico e pedagógico com produção de conhecimento, o que correspondeu a uma separação de instituições.

1. Publicado originalmente em 1937 sob o título A educação pública em S. Paulo. Neste texto utilizo a segunda edição, A educação na encruzilhada, de 1957. 
Conquanto o tom das posições fosse nacionalista, elas divergiram na sua especificação, que assumiu colorido moral, industrial, cultural ou religioso. Em qualquer dos casos, evidencia-se o compromisso com as elites dirigentes e o desejo dos intelectuais de interferirem nas políticas estatais para a área, candidatando-se ou ocupando propriamente postos na esfera governamental. A preocupação com a universidade e com a formação do professor estava ligada diretamente a projetos de domínio político.

A atuação, no Brasil, de Georges Dumas e Paul Fauconnet, professores franceses da Sorbonne, disseminou a idéia da necessidade de organizações dessa espécie para a formação do professor em nível superior baseada no modelo francês (Léon, 1967; Dumas, 1928; Fauconnet, 1927). Ao lado desse, também foi indicado o Teacher's College americano, dedicado à formação do professor, que conjugava ensino superior científico e profissional, resultante da adequação dos modelos alemão e inglês, especialmente os colleges (Souza Campos, 1940; Silveira, 1930; Lacombe, 1935).

Essa década foi importante porque, além de consolidar a crítica à formação do mestre, projetou sua institucionalização. Confiantes nas qualidades dos modelos internacionais conhecidos, os depoentes traçaram seus próprios objetivos. Tinham interesse na problemática já que eram professores, conviviam com a questão e seriam eles mesmos os professores das novas gerações de secundaristas. De outro lado, muitos ocupavam postos na hierarquia administrativa, o que Ihes dava a necessária autoridade para propor projetos.

O Instituto de Educação de São P a ulo

Fernando de Azevedo, membro destacado dessa intelectualidade, ao coordenar o referido inquérito teceu comentários que reproduzem 0 grau de indefinição presente, afirmando, contu- do, a universidade como lugar preferencial para abrigar a formação do professor secundário (1957, p. 190). Azevedo advogava que 0 preparo docente devia estar marcado por uma faceta técnica, tanto da ótica dos conteúdos de sua formação quanto da do local apropriado para tal, um instituto (1958a, p. 26-27). Segundo ele, os professores requeridos pela sociedade não existiam e precisavam ser formados eivados do "espírito de renovação", do sentimento de artífices da "consciência comum" - alma da nação - e de "ativo fermento" da unidade nacional. Conquanto as escolas normais pudessem continuar existindo, pleiteou como lugar privilegiado para a formação do mestre - "a mais preciosa das safras que recolhe a sociedade" - um "Instituto Superior de formação técnica" (Azevedo, 1937, p. 43). 0 professor deveria "conhecer os fins, os meios e os métodos do seu ensino e saber justificá-los cientificamente", sendo educador pela capacidade de produzir e organizar valores espirituais (Azevedo, 1958a, p. 138). Os argumentos produzidos pela ciência e pela história estariam na base de seu procedimento, técnico e científico, não resultando de interesses políticos menores. Por essa via explicou a necessidade da institucionalização da área em nível superior. O Instituto de Educação de São Paulo, resultado da reforma educacional realizada pelo intelectual em 1933, configurou-se, pois, como uma escola na qual os futuros docentes receberiam formação de nível superior, profissional. $^{2}$

Tal projeto retomava as proposições defendidas pelos depoentes no inquérito de 0 Estado de S. Paulo, especialmente as relativas à profissionalização do professor secundarista, seu maior trunfo político. A institucionaliza-

2. No primeiro nível funcionavam, para aplicação, jardim de infância, escola primária e escola secundária, fundamental (cinco anos) e complementar (um ano), condição para acesso à Escola de Professores. 0 segundo correspondia à Escola de Professores e oferecia estudos superiores. Decreto $n-5.846$, de 21 de fevereiro de 1933. 
ção da preparação superior desse profissional realizou uma idéia unânime no inquérito, porém numa perspectiva técnica. Embora valorizasse a produção de pesquisa, Azevedo não acentuou a produção da ciência como tarefa necessária à qualificação do mestre, claramente colocada pelos depoentes. De outro lado, imprimiu à instituição uma característica cultural, constituída pelo ideal de construção da "consciência nacional", fortemente colocada nos depoimentos dos inquiridos, a despeito de vinculados a ideários divergentes. Mas assim como nos depoimentos ficou evidenciada a instrumentalização da formação docente para a realização de um modelo de sociedade pautada em valores industrializantes e citadinos, também o Instituto de Educação trouxe essa marca.

A idéia de formação técnico-profissional estava amarrada a uma particular compreensão de ciência. Segundo Monarcha (1992), no caso da Psicologia e da Biologia, ocorreu uma apropriação da ciência sob forma instrumental, transformada em suporte de uma série de iniciativas no campo político, econômico e educacional. Seu uso deu-Ihe feição técnica, a partir da qual se podia exigir que os funcionários do Estado - ou as elites dominantes -, assim como os intelectuais, se pautassem por conduta técnica, aparentemente oposta à conduta política, própria da "tradição". Azevedo insistia no caráter técnico e profissional da preparação do mestre. Também os depoentes do inquérito se referiam à profissionalização do magistério admitindo que isso significava saber e saber ensinar, isto é, ter a ciência e a técnica adequadas para transmiti-la. 0 autor considera que Azevedo procurou articular a crítica empreendida no interior da classe dominante, assentada na reorientação do modo de produção capitalista.

A formação dos professores muitas vezes constituiu um dos elementos centrais do embate político, já que por ela o ideário "renovador" se realizaria junto à elite e ao povo. Assim, 0 Instituto de Educação pode ter resultado de um amálgama de idéias produzido por Azevedo.
Uma outra hipótese, mais consistente, poderia ser aventada no campo político. Sendo membro importante de uma facção cuja aspiração era o comando político do Estado e da nação, atuava no sentido de aglutinar apoios em torno desse projeto. Sintetizar as posições dos intelectuais paulistas em uma realização da administração pública de seu grupo - a "comunhão paulista" - poderia render outros frutos além dos pedagógicos (Cardoso, 1982). Por outro lado, no momento em que o inquérito se realizou, as águas políticas ainda não haviam se dividido claramente. As divergências entre as posições renovadoras e católicas, por exemplo, não estavam ainda em conflito aberto. Tal conflito ficará exposto a partir de 1930, repercutindo de modo contundente sobre a institucionalização universitária da formação do magistério no Brasil.

\section{A formação do professor no Instituto de Educação da Universidade de São Paulo}

Após a instituição pelo Governo Provisório de Getúlio Vargas do "modelo universitário" preferencial para a ordenação do ensino superior no país, o interventor de São Paulo, Armando de Salles Oliveira, fundou a Universidade de São Paulo, em 1934. Sua posterior regulamentação estabeleceu novas condições legais para a criação de universidades, admitindo a reunião de faculdades e institutos já existentes e a criação de outros. 0 estado de São Paulo criou, na USP, a Faculdade de Filosofia, Ciências e Letras - FFCL e incorporou 0 Instituto de Educação-IE.

Legalmente colocado como instituição formadora de professores de caráter técnico e profissionalizante, o IEUSP assumiu a produção de pesquisa e de conhecimento como parte de suas funções, levando a importante herança de formação superior dos intelectuais da educação, atribuição tradicional da Escola Normal da Praça. Sendo foco de vida e de 
cultura, a escola normal atingiria sua plenitude com a "radical transformação no sistema, para ajustá-lo às novas condições e exigências sociais, culturais e pedagógicas", segundo Azevedo, que "inaugurou nova época na história do ensino normal" (1953, p. 177).

Com dissensões internas, a hegemonia dessa geração, iniciada antes da criação da USP, conformou um pensamento e gerou uma intervenção que pretendeu deixar marcas na memória e na história da educação brasileira. A leitura que produziu sobre si mesma como "inauguradora" de um novo tempo - conquanto nem todos os catedráticos tivessem formulado esta intenção - encontrou feliz tradução nas palavras de Azevedo: "Um homem novo para um mundo novo". Foi no âmbito da criação das "almas", seja a do povo, seja a da elite, seja a da "alma mater" - a universidade - que o objetivo do Instituto de Educação da USP colocou-se (1958a, p. 89-95).

0 IEUSP reivindicou a "formação profissional de professores primários e secundários e de administradores escolares", por meio de cursos específicos aos quais agregavam- se "cursos extraordinários de aperfeiçoamento; de especialização e de extensão universitária". A "nota da redação" do primeiro número do Archivos do Instituto de Educação, publicado em setembro de 1935, observa:

\section{(...) instituto superior, de caráter nitidamente} profissional, preposto a preparar, aperfeiçoar e especializar professores, dos diversos graus, e administradores escolares ou, mais explicitamente, diretores e orientadores de ensino a que chamamos ainda "inspetores e delegados de en$\sin 0^{\prime \prime}(\ldots)$

Abandonando o recorte "puramente" propedêutico e retórico, atrasado, da formação tradicional, sustentada à custa de forte centralização e fiscalização, a adesão à técnica soou como momento libertador do trabalho docente a ser desenvolvido dentro dos mais rigorosos preceitos científicos. Se esta foi a principal função do IEUSP e se seu caráter profissional e técnico foi explicitamente assumido, tais desígnios não se realizariam apenas pelo ensino e pela aplicação da ciência. Parte de uma instituição universitária, cabia-Ihe ser também um "centro de pesquisas, nos diversos campos de estudos e investigação". Seu grande desiderato era imprimir ao ensino "um caráter acentuadamente experimental", no movimento "dos laboratórios ao ensino". Os laboratórios - Psicologia Educacional, Biologia Educacional, Pesquisas Sociais e Educacionais e Estatística foram fundamentais na vida do Instituto precisamente porque neles se operavam as "verificações objetivas" das teorias, as "experimentações", as "observações", as "práticas". Por seu intermédio permitia-se a demonstração, aos círculos intelectuais emergentes, da inexorabilidade da ciência e da correção - técnica, científica e moral - de suas teorias (Azevedo, 1946, p. 61). Seus professores atuavam no ensino, na pesquisa e na extensão - denominados cursos de conferências ou cursos livres - , as três grandes faces da "idéia universitária", presentes originalmente no projeto de fundação da USP, com ênfase na produção científica.

A Psicologia, ao lado da Biologia e da Sociologia, afirmadas como a "santíssima trindade" das ciências-fonte da Educação, possibilitariam ao campo pedagógico a realização de seu grande desígnio: construir uma ciência do homem (Debesse, 1970). Monarcha chama a atenção para a tríplice composição das Ciências da Educação, da qual resultou a

classificação dos fenômenos vivos em: orgânicos, psíquicos e sociais. Neste caso, dessas três ordens de fenômenos é tomado o conjunto de pressões que atravessa 0 indivíduo, daí a idéia de uma pedagogia experimental, daí a idéia de revolução copernicana, segundo a qual o 
aluno é posto como centro do processo de aprendizagem. Daí, portanto, a idéia do homem como um dado de observação. (Monarcha, 1992, p. 46)

Com base na ciência - especificamente na trindade referida - o mestre deveria conduzir o povo à "comunhão dos ideais", dos espíritos: em síntese, para a "nação". Entendia-se que a miséria do povo brasileiro era decorrente de sua extremada ignorância, legada pelo tradicional sistema escolar dualista que, beneficiando as camadas médias e as oligarquias, produziu uma supersafra de bacharéis, entregando as massas à indigência escolar. Estas encontravam-se dispersas e sem consciência pátria formada, fosse em função das idéias vigentes, sempre importadas, que desprezavam o "elemento nacional", fosse em função da imigração, que gerava a presença de inúmeras etnias em território brasileiro. 0 espaço mental estava, dessa perspectiva, por ser plasmado, moldado. Para lidar com essa massa praticamente informe foi tida como necessária a formação de uma "inteligência nacional", de uma "concepção de mundo brasileira", de uma teoria adequada às realidades nacionais. Sem essa "elite pensante", pouco se poderia fazer pelas massas inermes. Azevedo, diretor do IEUSP, afirmava que "civilizações se construíram sem a participação das massas, mas jamais se ouviu falar de uma construída sem a intervenção das elites".

Tal projeto, vasto, tinha à testa docentes da primeira "instituição do gênero no Brasil" destinada à formação de professores em nível universitário, correspondente, em sua maior parte, à última geração do anterior Instituto de Educação, antiga Escola Normal da Praça. Geração que se notabilizou pela produção teórica, pelos estudos publicados, pelo acesso à grande imprensa e periódicos, pelos cargos públicos ocupados e pela participação na fundação de inúmeras sociedades científicas a partir dos anos 1920 e 1930.
As cadeiras e os professores

Oito cadeiras exibiam o rol dos saberes que comporiam a formação pedagógica do professor a partir daquele momento: Biologia Educacional; Psicologia Educacional; Sociologia Educacional; Filosofia e História da Educação; Estatística Educacional e Educação Comparada; Administração e Legislação Escolar; Metodologia do Ensino Secundário; Metodologia do Ensino Primário. As cadeiras e matérias que compuseram a formação do professor em nível universitário demarcaram um momento importante na profissionalização do magistério. De certo modo, foi afastada de suas origens clássicas, agora atribuídas à formação secundária, aprofundando e detaIhando o corpo teórico a sustentar a referida formação, constituído de disciplinas que aportaram sua consistência científica à educação e ligaram-se, de certa forma, organicamente à área mediante 0 designativo "educacional" aposto na Biologia, Psicologia, Sociologia e Estatística. Para o magistério secundário, a cadeira de Matéria de Ensino foi separada da de Prática de Ensino, dividindo, por conseqüência, a formação específica da pedagógica. Tais indicações concerniam ao núcleo da proposta de formação do magistério, sendo oferecida na FFCL a formação específica e no IEUSP a pedagógica, o que implicava uma separação entre a formação no plano dos conteúdos do ensino, reduzida a formação pedagógica à manipulação dos meios de ensinar.

A formação do professor foi conduzida de modo a tornar-se progressivamente científica e dotada dos conhecimentos que Ihe permitissem aproximar-se da realidade social e escolar, tanto do ponto de vista da clientela atendida quanto de seu gerenciamento e dos conteúdos a compor, de um lado, as políticas públicas e, de outro, a mentalidade nacional. Nesse sentido, a escola foi tomada a partir de uma totalidade que envolvia o conhecimento 
da criança e do adolescente, o conhecimento da sociedade, o conhecimento da política educacional necessária para viabilizar o projeto abraçado e o conhecimento das condições para administração desse sistema.

No ápice da hierarquia docente encontrava-se o professor catedrático, cuja primeira geração foi nomeada pelo governo e depois mediante concurso público. Uma vez nomeado, era vitalício e inamovível, embora pudesse ser destituído caso cometesse alguma infração prevista na legislação. Obrigado a seis aulas semanais, receberia um percentual pelas aulas extras que viesse a assumir, mas impedido de lecionar mais de uma cadeira diferente da sua. 0 docente-livre era admitido por concurso público e nomeado por dez anos. Se decorridos cinco anos não tivesse publicado trabalhos e nem se desincumbido bem das tarefas de ensino, poderia ser excluído pela congregação. Seu trabalho estava diretamente ligado ao do catedrático, ganhando maior autonomia quando lecionava ou oferecia cursos de aperfeiçoamento e especialização em sua disciplina ou cursos equiparados aos dos catedráticos. Seu salário era variável, dependendo das atribuições que possuía. A única receita diretamente sua correspondia àquela que receberia dos alunos que pagassem pelos cursos equiparados que oferecesse.

Assistentes e subassistentes cooperavam com o catedrático e auxiliavam os alunos; colaboravam nos seminários e excursões; participavam de comissões. Sua dependência do catedrático era extrema, sendo nomeado pelo governo apenas se indicado pelo primeiro. 0 subassistente só poderia ingressar por concurso e após escolha do catedrático. Os professores contratados, por um máximo de três anos, equivaliam em atribuições ao catedrático e eram previstos para situações de dificuldades.

Ao ser anexado à USP, o Instituto de Educação herdou o quadro docente da Escola de Professores do anterior Instituto de Educação. ${ }^{3}$ Roldão Lopes de Barros em março de 1933 foi nomeado professor-chefe da 1a Seção, Educação, da Escola de Professores do Instituto de Educação. Em abril de 1911 havia assumido a cadeira de Pedagogia e Educação Cívica na Escola Normal Primária, anexa à Escola Normal de S. Paulo e, em fevereiro de 1931, a 2a cadeira, Pedagogia Geral e História da Educação, do Instituto Pedagógico de São Paulo. Em 1934 a 1a Seção, de Educação, ficou sob sua responsabilidade.

Antônio Ferreira de Almeida Jr. em 1909 formou-se na Escola Normal da Praça. Em 1921 formou-se na Faculdade de Medicina, doutorando-se em 1922. Em 1920 foi nomeado professor de Biologia na Escola Normal do Brás, depois Padre Anchieta. Pertenceu nesse período ao Instituto de Higiene e, em 1931, foi transferido para o curso de aperfeiçoamento do Instituto Pedagógico. Em 1933, tornou-se professor de Biologia do IE e em 1934 do IEUSP. Foi fundador do Liceu Rio Branco, com Lourenço Filho, sendo seu diretor até 1934. Em março de 1933 foi nomeado professor-chefe da 2a Seção, Biologia Aplicada à Educação, da Escola de Professores do IE. Desde maio de 1919 trabalhava na Escola Normal de S. Paulo, deixando seu cargo na Escola Modelo isolada da capital, assumindo em agosto do mesmo ano o posto de professor na Escola Complementar, anexa, no lugar de Gabriel Ortiz. Em maio de 1920, foi nomeado auxiliar de diretor da Escola Normal da Capital e, em fevereiro de 1931, lente da $1^{a}$ Cadeira, Fisiologia Aplicada à Higiene e ao Trabalho, no Instituto Pedagógico de São Paulo. Em 1934, ficou responsável pela 2a Seção, de Biologia Educacional.

Noemy Marques da Silveira, depois Noemy da Silveira Rudolpher, em janeiro de 1933 tornou-se diretora do Serviço de

3. O Código de Educação previa que a Escola de Professores ofereceria cursos de formação do professor primário e secundário. Entretanto, o segundo não funcionou. Para maiores informações cf. Evangelista (1997). 
Psicologia Aplicada do Curso de Aperfeiçoamento do Instituto "Caetano de Campos". Desde junho de 1920 atuava como substituta efetiva da Escola Modelo "Caetano de Campos", anexa à Escola Normal da Capital. Em maio de 1928 foi nomeada substituta em comissão do professor Clemente Quaglio, responsável pelo Gabinete de Psicologia da Escola Normal da Capital, durante sua licença. Em 1934 assumiu a 3ạ Seção, de Psicologia Educacional e, em 1935, a 2ª Cadeira, Psicologia Educacional, primeiro comissionada e depois, em 1936, como catedrática.

Fernando de Azevedo em 1918 formou-se na Escola de Direito de São Paulo. Entre 1923 e 1926 foi crítico no jornal O Estado de S. Paulo. A partir dos anos 1920 iniciou no magistério, sendo professor de Literatura e Língua Latina na Escola Normal da Praça; foi diretor da Instrução Pública no Distrito Federal entre 1927 e 1930; foi professor de Sociologia no Curso de Aperfeiçoamento do Instituto Pedagógico em 1931 e fundou o IE em 1933. Em março de 1933 foi nomeado professor-chefe da 4 a Seção, Sociologia Educacional, da Escola de Professores do Instituto de Educação. Sua primeira nomeação data de fevereiro de 1921, quando se tornou lente de Latim e Literatura no Curso Secundário da Escola Normal da Capital. Em julho de 1925 assumiu o cargo de lente de Latim e Literatura na Escola Normal da Capital. Mais tarde, em fevereiro de 1931, tornou-se lente da 4a - Cadeira, Sociologia, no Instituto Pedagógico de São Paulo.

Em 1935 o quadro docente ficou, então, assim constituído: Oscar Araújo, preparador da 1ā cadeira, Biologia Educacional, passou a assistente por indicação de Almeida J r., mas deixou 0 cargo nesse ano. Na 2ª cadeira, Psicologia Educacional, permanecia comissionada Noemy da S. Rudolpher. Fernando de Azevedo permaneceu responsável pela 3a cadeira, Sociologia Educacional. A 4a cadeira, Filosofia e História da Educação, ficou constituída apenas por seu catedrático, Roldão Lopes de Barros. Milton Camargo Rodri- gues foi nomeado professor interino da $5^{a}$ cadeira, Estatística Educacional e Educação Comparada; passando após concurso, em outubro de 1935, a catedrático. Para a 6a cadeira, Administração e Legislação Escolar, indicou-se interinamente Roldão Lopes de Barros. A 7ạ cadeira, Metodologia do Ensino Primário, ficou vaga. Foram contratados para a 8a cadeira, M etodologia do Ensino Secundário, João Alfredo dos Santos, J oão Augusto de Toledo, Ernestina Giordano e Reynaldo Kuntz Busch. Durante o período ocorreram inúmeras mudanças. Entretanto, os catedráticos permaneceram praticamente os mesmos, ocorrendo o maior número de alteração entre os assistentes.

Após a extinção do IEUSP seus profissionais foram distribuídos por diferentes lugares, sem que se possa precisá-los e tampouco as datas. Os funcionários administrativos permaneceram na Escola Normal Modelo (Decreto $\mathrm{n}-9.256$, de 22 de junho de 1938). Em junho de 1938 o IEUSP contava com 69 professores, dos quais 42 permaneceram na Escola Normal Modelo - ENM, incluídos os da escola secundária, primária e do jardim da infância. 0 número total dos afastados correspondeu, portanto, a 37, sendo que um havia se licenciado antes do episódio, um havia solicitado exoneração e sete não foram identificados. Os 28 restantes foram assim alocados: Antônio Ferreira de Almeida J r. (FFCL) Sylvio de Almeida Toledo - aposentou-se; Maria de Lourdes B. dos Santos (ENM); Noemy da Silveira Rudolpher (FFCL); Olga Strehlneek (FFCL e ENM); Celisa de R. Arruda (FFCL); Fernando de Azevedo - FFCL; Achiles

\footnotetext{
4. Biografia e dados sobre Almeida Júnior. Folha avulsa. 1971 Boletim de freqüência. 1938; Compromisso do pessoal docente e administrativo. 1933; Folha de Pagamento. 1933/1934; J ustificativa das despesas. 1938, 1939; Registro de ofícios. 1936 a 1939. Termos de compromisso. 1894; Termo de compromisso de pessoal nomeado para a Escola Normal da Capital. 1911, 1918, 1918/1930; Termos de compromisso de funcionário para a escola normal da capital e estabelecimentos anexos. 1930. Informações adicionais quanto aos destinos dos profissionais do IEUSP, cf. Evangelista (1997).
} 
Archêro J r. - FFCL; Roldão Lopes de Barros (FFCL); Emilio Willens (FFCL); Milton da S.C. Rodrigues (FFCL); Affonso P. de T. Piza (Exonerado); J osé Querino Ribeiro (FFCL); Ramiro A.C. de Almeida (sem dados); Dora Caldeira de Barros Pastorino (FFCL); Onofre de Arruda Penteado J r. (FFCL e ENM); Raphael Grisi (ENM); Reynaldo Kuntz Busch (sem dados); Ernestina Giordano (FFCL); Nelson da Cunha Azevedo (FFCL) e Zuleika de Barros Ferreira (ENM).

0 corpo de assistentes do Laboratório de Psicologia foi transferido para o Departamento de Educação, antes Diretoria do Ensino, fazendo agora parte da Diretoria do Serviço de Orientação Pedagógica (Decreto no 9.255, de 22 de junho de 1938). Os laboratórios de Biologia Educacional, de Pesquisas Sociais e de Estatística foram encerrados e seus assistentes ficaram na FFCL. Após a transferência, esse conjunto de profissionais iniciou sua atuação na 4a Seção da Faculdade de Filosofia, Ciências e Letras, a de Educação. A partir de 1941, no A nuário organizado por Azevedo, foi possível encontrar informações relativas a professores do IEUSP atuando nos cursos de Pedagogia e Didática. Não obstante 0 decreto-lei de reorganização da FFCL datar de 1942, o Decreto-lei federal $\mathrm{n}-1.202$, de 8 de abril, ao qual se adequou, data de 1939. Isto significa que a FFCL já estava implantando o modelo federal antes mesmo que fosse decretada sua organização na USP.

\section{Os cursos oferecidos}

0 Instituto oferecia cursos superiores, denominados normais: Curso de Administradores Escolares, ao custo de $360 \$ 000$ ao ano por aluno; Curso de Formação Pedagógica do Professor Secundário, 350\$000; e Curso de Formação do Professor Primário, 600\$000. Para o de professor primário, exigia-se um exame de admissão ou a aprovação no segundo ano do Colégio Universitário; e para o de professor secundário, estar cursando ou ter cursado alguma das seções da Faculdade de Filosofia, Ciências e Letras.
Além desses, oferecia os extraordinários: Cursos Equiparados aos Normais, dados pelos docentes-livres; Cursos de Aperfeiçoamento, que custavam 230\$000; Curso de Especialização, que custou 130\$000; Cursos de Extensão Universitária e Cursos Livres.

0 de Administradores Escolares tinha em seu currículo sete matérias: Biologia Educacional (Higiene Escolar), Psicologia Educacional, Sociologia Educacional, Filosofia da Educação, Educação Comparada, Estatística e Administração, Legislação Escolar. Da Formação do Professor Primário participavam: Biologia Educacional, Psicologia Educacional, Sociologia Educacional, História e Filosofia da Educação, Educação Comparada e Metodologia; e a Formação do Professor Secundário exigia: Biologia Educacional Aplicada ao Adolescente, Psicologia Educacional, Sociologia Educacional, História e Filosofia da Educação, Educação Secundária e Comparada e Metodologia do Ensino Secundário, a qual contaria com assistentes para as matérias isoladas.

Esse padrão acadêmico de professor foi precisado a partir de abril de 1935, quando se publicou o Regulamento do IEUSP. As modificações disciplinares desenharam mais bem o projeto de preparação do mestre. 0 primeiro curso, Formação do Professor Primário, ofereceu, na primeira série, Biologia Educacional, Psicologia Educacional, Sociologia Educacional e Matérias e Prática de Ensino Primário. Na segunda, Biologia Educacional (Higiene Escolar), Psicologia Educacional, História e Filosofia da Educação, Educação Comparada e M atérias e Prática de Ensino Primário, que acontecia ao longo do curso. Uma vez concluído, o aluno recebia 0 diploma de professor primário. 0 segundo, de Administradores Escolares, exigiu as disciplinas de Biologia Educacional (Higiene Escolar), Psicologia Educacional, Estatística e Administração e Legislação Escolar (bases), no primeiro ano e, no segundo, Sociologia 
Educacional, Psicologia Educacional, Educação Comparada e Administração e Legislação Escolar (Sistemas e Técnicas). A conclusão dava direito ao Diploma de Administrador Escolar. Em 1936 iniciou o Curso de Formação Pedagógica do Professor Secundário. No primeiro semestre foram trabalhadas as cadeiras de Biologia Educacional Aplicada ao Adolescente, Psicologia Educacional, Sociologia Educacional e Metodologia do Ensino Secundário; no segundo, História e Filosofia da Educação, Educação Secundária Comparada e Metodologia do Ensino Secundário. Cursado após a licenciatura obtida na FFCL, admitia também a formação simultânea ao terceiro ano daquela Faculdade, concedendo o diploma de professor secundário.

Os Cursos Extraordinários, com organização e duração variadas, dependiam da aprovação da congregação e das determinações estatutárias da Universidade e sob a forma de Cursos Equiparados, de Aperfeiçoamento, de Especialização, Livres e de Extensão Universitária denominados Cursos de Conferências. Além dessas atividades componentes do núcleo propriamente universitário do Instituto, as Escolas Anexas estavam contempladas no regulamento; o Título II, art. 104, indicava que "dependem, administrativa e tecnicamente, do Instituto de Educação, como anexos seus, destinados principalmente à observação e experimentação pedagógica", mas sob jurisdição do Departamento de Educação da Secretaria dos Negócios da Educação e Saúde Pública. Desse modo, essas escolas mantinham relações estreitas com os cursos superiores, pois parte das atividades eram realizadas em conjunto e, em certa medida, delas dependiam para experimentação, prática e aplicação dos saberes a serem aprendidos pelo mestre a ser formado. Compunha também o quadro das escolas anexas a 4a Seção do Colégio Universitário, com dois anos, posterior ao Curso Fundamental de cinco anos, inicialmente denominado Curso Complementar.
É possível afirmar que o número aproximado de alunos no IEUSP entre 1934 e junho de 1938 foi de 1.017. Nesses números há aumento dos alunos de origem interiorana, a despeito de no último ano ter se registrado um decréscimo percentual nessa presença. De outro lado, a alta incidência da presença feminina é visível: aproximadamente $88 \%$ contra $12 \%$ de homens. Relativamente à faixa etária, girou em torno de 22 anos.

\section{Conclusão}

A universitarização do preparo do professor, como se pode ver, ocorreu em cursos de diferentes matizes e em conjunto com a Faculdade de Filosofia, Ciências e Letras da USP. A primeira geração de professores universitários constituiu-se simultaneamente à primeira geração de professores secundários e primários. Entretanto, apesar de ser uma das respostas à demanda por qualificação profissional e do peso que essa formação vinha tendo como modelo para outras experiências o Instituto teve sua vida violentamente encerrada. Forças políticas ligadas ao estado intervencionista de Ademar de Barros e à Igreja Católica finalizam a primeira experiência brasileira de formação de professores primários e secundários em nível universitário a exemplo do que ocorreu também com a Universidade do Distrito Federal no mesmo período, ainda que de modo muito mais grave dado que naquele caso a ditadura getulista encerrou a universidade e não apenas a Escola de Educação (Decreto estadual no 9.268-A, de 25.06.1938, e Decreto estadual no. 9.403, de 10.08.1938).

A significativa inserção social, política e intelectual dos catedráticos do IEUSP e a contribuição que deram com pesquisas e estudos não foram suficientes para impedir que suas portas fossem cerradas, em 1938, pelo Estado Novo. 


\section{Referências bibliográficas}

CARDOSO, I. A universidade da comunhão paulista. São Paulo: Cortez/AA, 1982.

CARVALHO, M. M. C. Molde nacional e fôrma cívica: higiene, moral e trabalho no projeto da ABE (1924-1931). São Paulo, 1986. Tese (Doutorado). Faculdade de Educação da USP.

DEBESSE, M. L'enfance dans I'histoire de la psychologie. In: ZAZZO, R. Traité de psichologie de l'enfant. Paris: Presses Universitaire de France, 1970.

EVANGELISTA, Olinda. A formação do professor em nível universitário: 0 Instituto de educação da Universidade de São Paulo (1934 - 1938). São Paulo, 1997. Tese (Doutorado). PUC/SP.

LÉON, A. Histoire de l'enseignementen en France. Paris: Presses Universitaires de France, 1967.

LIMONGI, F. Mentores e clientela da Universidade de São Paulo. In: MICELI, S. (org.) História das Ciências Sociais no Brasil. São Paulo: Vértice, 1989.

MONARCHA, C. As três fontes da pedagogia científica: a psicologia, a sociologia e a biologia. Didática, São Paulo, v. 28, p. $1-23,1992$.

TANURI, L. A escola normal no Estado de São Paulo - 1890-1930. São Paulo: FEUSP, 1979.

TOLEDO, M. R. de A. Fernando de Azevedo e "A Cultura Brasileira" ou as aventuras e desventuras do criador e da criatura. São Paulo, 1995. Dissertação (Mestrado), PUC/SP.

\section{Fontes documentais}

AZEVEDO, F. A educação e seus problemas. 3.ed. São Paulo: Melhoramentos, 1953.

. A educação entre dois mundos. São Paulo: Melhoramentos, 1958a.

A educação na encruzilhada: problemas e discussões; inquérito para o Estado de S.Paulo. 2.ed. São Paulo: Melhoramentos, 1957.

Seguindo meu caminho: conferências sobre educação e cultura. São Paulo: Nacional, 1946.

BRASIL. Decreto federal $n^{\circ} .19851$, de 11 de abril de 1931. Estatutos das Universidades Brasileiras. Ministério de Estado da Educação e Saúde Pública. Rio de J aneiro: Imprensa Nacional, 1931.

BRASIL. Regulamentação do art. 3엉 Decreto n‥19851, de 11 de abril de 1931. Decretos Federais e Estaduais. Decretos Federais e Estaduais. São Paulo. Imprensa Oficial do Estado, 1934.

DUMAS, G. Faculdade de Letras e Faculdade de Ciências. Educação, São Paulo, v. 2, n. 1, p. 97-100, jan. 1928.

FAUCONNET, P. Estrutura e organização das universidades. Educação, São Paulo, v. 1, n. 2, p. 113-126, nov. 1927.

LACOMBE, L. J. Considerações sobre o problema da organização das faculdades de educação. Revista Brasileira de Pedagogia, Rio de Janeiro, ano II, v.lll, n. 11, p. 5-11, fev. 1935.

SÃO PAULO. Decreto n 5.884, de 21 de abril de 1933. Código de Educação. Coleção das Leis e Decretos do Estado de São Paulo. Tomo XLIII, São Paulo: Imprensa Oficial, 1933.

SÃO PAULO. Decreto n ${ }^{\circ} 6.283$, de 25 de janeiro de 1934. Cria a USP - e dá outras providências. Decretos Federais e Estaduais. Ensino Universitário. São Paulo. Imprensa Oficial do Estado, 1934. 
SÃO PAULO. Decreto no 3.356, de 31 de maio de 1921. Regulamenta a Lei 1750 de 08 de dezembro de 1920. Atos do Poder Executivo. Coleção das Leis e Decretos do Estado de São Paulo. Tomo XXXI. São Paulo, Tipografia do Diário Oficial. 1922.

SÃO PAULO. Decreto no 9.268-A, de 25 de junho de 1938. Extingue o Instituto de Educação da USP. s.n.t.

SÃO PAULO. Decreto no 9.403 , de 10 de agosto de 1938. Transfere os catedráticos da IEUSP para Faculdade de Filosofia, Ciências e Letras da USP. s.n.t.

SÃO PAULO. Lei n 1.750, de 08 de dezembro de 1920. Cria a Faculdade de Educação. Consolidação das Leis, Decretos e Decisões sobre o Ensino Primário e Normal.

SOUZA CAMPOS, E. de. Educação superior no Brasil. Rio de J aneiro: Ministério da Educação, 1940.

Recebido em 04.05.01

Aprovado em 16.10.01

Olinda Evangelista é doutora em História e Filosofia da Educação pela Pontifícia Universidade Católica de São Paulo, professora no curso de Licenciatura em Pedagogia e no curso de Mestrado em Educação no Departamento de Estudos Especializados em Educação do Centro de Ciências da Educação da Universidade Federal de Santa Catarina. 